\title{
Mediating role of job satisfaction in the relationship between motivation, perceived support, training and perceived commitment
}

Neda Sadat Sanei ${ }^{1}$, Mojtaba Poursalimi ${ }^{2}$

Journal of Research \& Health

Social Development \& Health Promotion Research Center

Vol. 8, No. 1, Jan \& Feb 2018 Pages: 3- 11

DOI: 10.29252/acadpub.jrh.8.1.3

Original Article

1. Department of Business Management, Neyshabur Branch, Islamic Azad University, Neyshabur, Iran

2. Correspondence to: Department of Management, School of Economics and Administrative Sciences, Ferdowsi University of Mashhad, Mashhad, Iran Email: poursalimi@ferdowsi.um.ac.ir

Received: 11 Apr 2016 Accepted: 11 Jun 2016

How to cite this article: Sanei NS, Poursalimi M. Mediating role of job satisfaction in the relationship between motivation, perceived support, training and perceived commitment. J Research \& Health2018; 8(1): 3- 11.

\begin{abstract}
Motivation as a psychological factor can affect the mental health of employees and consequently the health of work place. It has been recently concerned in the social science literature. The present study aimed to assess the mediating effect of job satisfaction on the relation of motivation, perceived support and training to perceived commitment. The data study analyzed in the structural equation modeling method. The data were gathered in library field, and, also using questionnaire. The data were achieved from staff of Sabzevar city municipality using validity and reliability approved questionnaires. For validity, face and construct validity and for reliability, Cronbach's alpha was used. Finally, data from 159 questionnaires were analyzed. The findings showed that motivation, perceived support and training had positive significant effects on normative and continuance commitment of employees. Also, positive significant effect of job satisfaction on continuance and normative commitment was confirmed. In addition, the findings of this study indicated positive effect of motivation, perceived support and training on perceived commitment with mediating role of job satisfaction. In other words, the more motivation, perceived support and training are, the more job satisfaction will be, which in turn can result in the increased continuance and normative commitment.
\end{abstract}

Keywords: Commitment, Job Satisfaction, Motivation, Support

\section{Introduction}

Managers are looking for commitment from their employees by different approaches. Highly committed employees are eager to have more effort for the organization. A strong attachment to the organization enables employees to have more adaptive capabilities and possesses more responsiveness to changes in customer demands and leads to compliance with environmental pressures and constraints
[1]. Committed human resources make an organization formidable. There is a point in internal marketing subject indicating that employees make inter-organization internal market [2]. In service organizations such as municipalities, hiring talent employees and creating steady perceived commitment in the employees and also training and motivating them is necessary for doing services such as 
scavenging. Absence of this commitment in employees of municipalities can lead to conflict, downbeat, increase of employee absence, decrease of their efficiency, and decrease of customer satisfaction. It seems that despite the significance of this issue, commitment of employees in municipalities has been less concerned in comparison with other factors affecting the success of the organization. Therefore, this issue was investigated in the present study. Ballantyne asserted that selection and employment, motivation, and perceived support in employees are important components of organization [3]. This means that change is needed in the case of employee activities directed at the development of organization. This change requires proper selection of employees, training and motivating them. In fact, training and teaching employee leads to the feeling of discomfort about leaving the organization and makes him/her interested in staying in the organization [4]. Managers are seeking to provide employees' needs in a manner that make them motivated and customer oriented [5]. The concept of perceived support is hidden in social exchange theory which has been used to understand the relations between managers and employees [6]. In this study, the perceived commitment implies employees' commitments to their organization. Different people have defined commitment in different ways. Some of them are reviewed below:

Porter et al. define perceived commitment as accepting organization values and getting involved in the organization. They believe that its measuring criteria involve motivation, desire to continue and accept the values of the organization which are key factors leading to the organization finance success and its competitive advantages [7]. Yaghoubi [8] defines perceived commitment as employee's bonding with the organization which is determined by three factors: a strong belief and acceptance about the goals and values of the organization (emotional commitment), tendency to be hard work for the organization (continuance commitment), and a strong desire to stay in the organization (normative commitment) [8].
Allen and Meyer present a three-part model for perceived commitment including normative commitment, emotional commitment, and continuance commitment that in the present study normative and continuance commitment are more considered [9]. Job satisfaction is an important factor to increase performance and also promote individual satisfactions. Fisher and Hanna consider job satisfaction as a mental factor and define it as an emotional adaptation with job and working conditions. It means that if job provide suitable conditions for individuals, they will have job satisfaction; but if job does not generate satisfaction and enjoy for individuals, they will start job blaming and they will leave their job if they can [10]. Khalaf Ahmad and ALBorie [11] had an inspection on the effect of motivation, perceived support and training on job satisfaction and perceived commitment in Saudi Arabia. They found the motivation, perceived support and training have a positive significant effect on job satisfaction and perceived commitment among staffs of hospitals in Saudi Arabia [11]. Ting conducted a study on the motivation, perceived support and training effect on perceived commitment regarding mediating role of job challenges and job satisfaction. He found that motivation, perceived support and training, job challenges and job satisfaction have positive significant effects on perceived commitment [12]. In this study we have tried to answer this question: "Is there the mediating role of job satisfaction in the relation of motivation, perceived support and training to perceived commitment?" This relation has been shown integrated by providing a conceptual model. In this part, the conceptual model offered in Figure 1 was employed to investigate the effect of motivation, perceived support and training on perceived commitment with mediating role of job satisfaction based on Ahmad Khalaf and Al-Borie model [11]. In the conceptual framework of this study, perceived support, training, motivation as independent variables, job satisfaction as the mediating variable and perceived commitment which consists of continuance commitment 
and normative commitment as the dependent variable are presented.

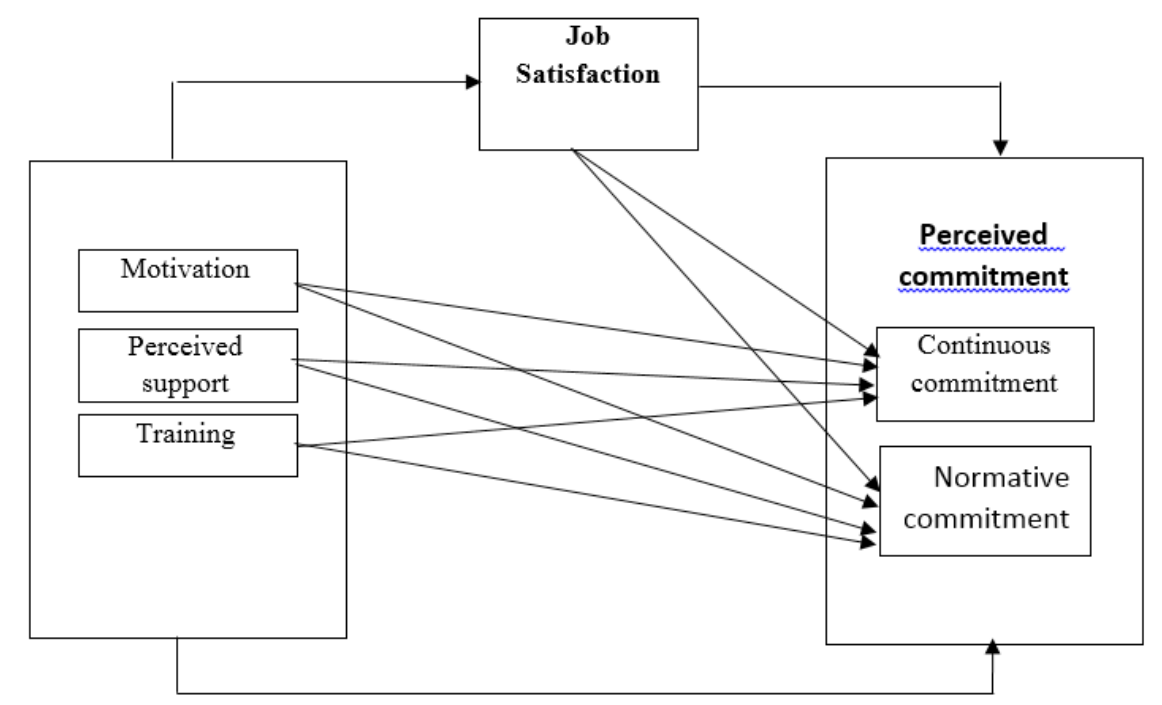

Figure 1 Conceputal model

\section{Method}

In terms of methodology, this is an applied, survey-causal research. The structural equation modeling was used to analyze data. For measuring the variables, according to Khalaf Ahmad and AL-Borie [11] and Allen and Meyer [9] and Spector [13], a questionnaire with 28 items was designed. This questionnaire measures 5 variables including motivation, perceived support, training, perceived commitment, and job satisfaction of employee. In order to adapt the questionnaire with commercial platform of Iranian organizations, the opinions of experts in this domain were gathered and applied. The face validity of final questionnaire was confirmed by investigating the opinions of management experts. Meanwhile, the structural validity of questionnaire was investigated by confirmatory functional analysis technique. The validity of dimensions and items of relative constructs were also confirmed. The constructs of motivation, perceived support, and training were measured using Khalaf-Ahmad and Al-Borie [11] instruments. Also, perceived commitment was measured by 5 dimension measures of Allen and Meyer. Finally, job satisfaction was determined using Specter instruments [13] by 5 questions. It is worth noting that all items of questionnaire were evaluated using 5-point Likert scale (from strongly agree to strongly disagree). The internal consistency of used instrument was also evaluated by Cronbach's alpha coefficient as reported in Table 1. Given that Cronbach's alpha coefficient in all questionnaire variables is more than 0.7 , it can be said that the questionnaire had a good reliability. Employees of Sabzevar city municipality were the participants of this study. According to available data, the total number of employees was estimated about 269 at the date of research. Because of the applied nature of the present study the sample must be representative for the statistical population if a good generalizability to the community is desired. So, simple random sampling method was used to select participants. To this end, a list of names for employees was prepared and by throwing balls, 159 participants were randomly selected. Firstly, a prototype of the questionnaire was pre-tested on 30 participants of same population with a standard deviation of 50\% shared in Cochran's formula. By making an estimation at 95 percent confidence level, the minimum number of sample size was determined as 159. Because of the probability of none-return questionnaires, 180 questionnaires were distributed randomly among the employees and 159 of them were returned. Cochran's formula values are shown in Figure 2. Finally, this number of eligible questionnaires was used in the data analysis. In 
the following formula, the maximum permissible error (d) of 0.05 , the confidence level of 0.95 , $\mathrm{t}=1.96$, $\mathrm{p}$ and $\mathrm{q}$ equal to 0.5 were applied to give the sample size $\mathrm{N}=159$. $\mathrm{P}$ was considered equal to 0.5 because if $p=0.5, \mathrm{~N}$ finds its maximum possible value and this causes the sample large enough [14].

$$
N=\frac{\frac{t^{2} p q}{d^{2}}}{1+\frac{1}{N}\left(\frac{t^{2} p q}{d^{2}}-1\right)}
$$

In this study, the gathered data were analyzed statistically for hypotheses. The present study included 4 primary hypotheses and 11 secondary hypotheses that were checked by Lisrel 8.8 software. The data were analyzed at descriptive and inferential levels. In order to describe the relevant data by SPSS software, relative frequency and percentage frequency were shown on diagrams and at inferential level after inspecting the reliability of questionnaire, the structural equation modeling (SEM) was used for surveying the relations between variables.

Table 1 The results of reliability test

\begin{tabular}{lcccccc}
\hline Variables & $\begin{array}{c}\text { Perceived } \\
\text { support }\end{array}$ & Training & Motivation & $\begin{array}{c}\text { Job } \\
\text { satisfaction }\end{array}$ & $\begin{array}{c}\text { Continuance } \\
\text { commitment }\end{array}$ & $\begin{array}{c}\text { Normative } \\
\text { commitment }\end{array}$ \\
\hline $\begin{array}{l}\text { Cronbach's } \\
\text { alpha }\end{array}$ & 0.7 & 0.742 & 0.795 & 0.766 & 0.805 & 0.792 \\
\hline $\mathrm{p}<0.05$ & & & & & & \\
\hline
\end{tabular}

\section{Results}

Characteristics of respondents in this study were surveyed by variables such as age, gender, work experience, education level, and marriage status. The based on these results, the most frequent of men, the most aged between
36-45 and the majority of married. Also ,are the most people BSc (Bachelor of Sciences) education and work experience between 1115 years. The following Table 2 summarizes the obtained results.

Table 2 Characteristics of respondents

\begin{tabular}{|c|c|c|}
\hline Demographic variables & State & Frequency $(\%)$ \\
\hline \multirow{2}{*}{ Gender } & Woman & 28.9 \\
\hline & Man & 71.1 \\
\hline \multirow{5}{*}{ Age } & $<25$ & 9.4 \\
\hline & $25-35$ & 27.7 \\
\hline & $36-45$ & 33.3 \\
\hline & $46-55$ & 20.2 \\
\hline & $>55$ & 9.4 \\
\hline \multirow{3}{*}{ Education } & Diploma and upper diploma & 29.5 \\
\hline & BSc. & 54.1 \\
\hline & MSc. & 16.4 \\
\hline \multirow{6}{*}{ Job Experience } & $<5$ & 8.8 \\
\hline & $5-10$ & 19.5 \\
\hline & $11-15$ & 34.6 \\
\hline & $16-20$ & 24.5 \\
\hline & $21-25$ & 8.2 \\
\hline & $>25$ & 4.4 \\
\hline \multirow{2}{*}{ Marriage status } & Married & 81.8 \\
\hline & Single & 18.2 \\
\hline
\end{tabular}


The normal distribution of variables on questionnaire was examined by KolmogorovSmirnov test in order to use the likelihood ratio test (Maximum likelihood) in the structural equations. Since the significance level of test for all variables was set at 0.05 , the hypothesis of normal distribution of variables was accepted; so we can use ratio method in the structural equation modeling. Also, before evaluating the proposed structural model, it is necessary to perform confirmatory functional analysis in order to investigate the significance of questionnaire items loading on related structures. Also, it is necessary to ensure about the capability of measuring models (Latent variables) for predicting the path coefficients. The results of confirmatory factor analysis for measuring models are shown in Table 3.

\begin{tabular}{|c|c|c|c|}
\hline Variables & $\begin{array}{l}\text { Number of } \\
\text { question }\end{array}$ & Factor loading & t-value \\
\hline \multirow{5}{*}{$\begin{array}{l}\text { Perceived } \\
\text { support }\end{array}$} & ps1 & 0.98 & 9.23 \\
\hline & ps2 & 0.64 & 8.93 \\
\hline & ps3 & 0.52 & 6.17 \\
\hline & ps4 & 0.38 & 5.31 \\
\hline & ps 5 & 0.58 & 4.43 \\
\hline \multirow{5}{*}{ Training } & edu1 & 0.51 & 5.36 \\
\hline & edu2 & 0.76 & 7.71 \\
\hline & edu3 & 0.59 & 8.99 \\
\hline & edu4 & 0.4 & 2.38 \\
\hline & edu5 & 0.44 & 4.22 \\
\hline \multirow{4}{*}{ Motivation } & mot1 & 0.48 & 2.51 \\
\hline & $\operatorname{mot} 2$ & 0.35 & 2.68 \\
\hline & $\operatorname{mot} 3$ & 0.49 & 2.13 \\
\hline & $\operatorname{mot} 4$ & 0.52 & 4.65 \\
\hline \multirow{5}{*}{$\begin{array}{c}\text { Job } \\
\text { satisfaction }\end{array}$} & js1 & 0.31 & 6.77 \\
\hline & js2 & 0.47 & 3.95 \\
\hline & js3 & 0.56 & 7.85 \\
\hline & js4 & 0.35 & 8.4 \\
\hline & js 5 & 0.43 & 8.85 \\
\hline \multirow{4}{*}{$\begin{array}{l}\text { Continuance } \\
\text { commitment }\end{array}$} & $\mathrm{cc} 1$ & 0.47 & 4.57 \\
\hline & $\operatorname{cc} 2$ & 0.39 & 8.9 \\
\hline & $\operatorname{cc} 3$ & 0.52 & 4.22 \\
\hline & $\operatorname{cc} 4$ & 0.54 & 5.33 \\
\hline \multirow{5}{*}{$\begin{array}{l}\text { Normative } \\
\text { commitment }\end{array}$} & nc1 & 0.77 & 7.8 \\
\hline & nc2 & 0.84 & 6.69 \\
\hline & nc3 & 0.69 & 5.01 \\
\hline & nc4 & 0.46 & 2.27 \\
\hline & nc5 & 0.53 & 6.77 \\
\hline
\end{tabular}

Then, using Lisrel software, each of 5 research variables was fitted to confirmatory factor analysis (CFA) models and the quality of fit was evaluated by regression coefficients or factor loadings significance and model fitting indices. The results showed that the factor loading of all questionnaire items was significant in the confidence level of $95 \%$ (with significance values greater than 1.96 as well as factorloading greater than 0.3); so all of them were used as bases for further analysis and examining the research hypotheses. Fitting model means that how much our model is adapted with the relevant data. In the structural equation 
analysis, after parameters estimation and before making interpretation, it is necessary to ensure about model fitting. Model fitting indices were listed in the following Table. RMSEA value is 0.084 and since it is less than 0.1 , it indicates that the mean square error of the model is suitable and model is accepted. Also, $\chi^{2}$ value of freedom degree is between 1 and 3 and values of goodness for-fit index (GFI), comparative fit index (CFI), and normed fit index (NFI) is more than 0.9 which indicate that the research variables are measured by a good model. With regard to confirmed questionnaire reliability and model fitting, we evaluated the hypothesis using confirmed dimensions of participant in the next part. In order to test hypothesis, we used structural model, standardized route coefficients, and corresponding significance values. The structural model has been shown in Figure 2.

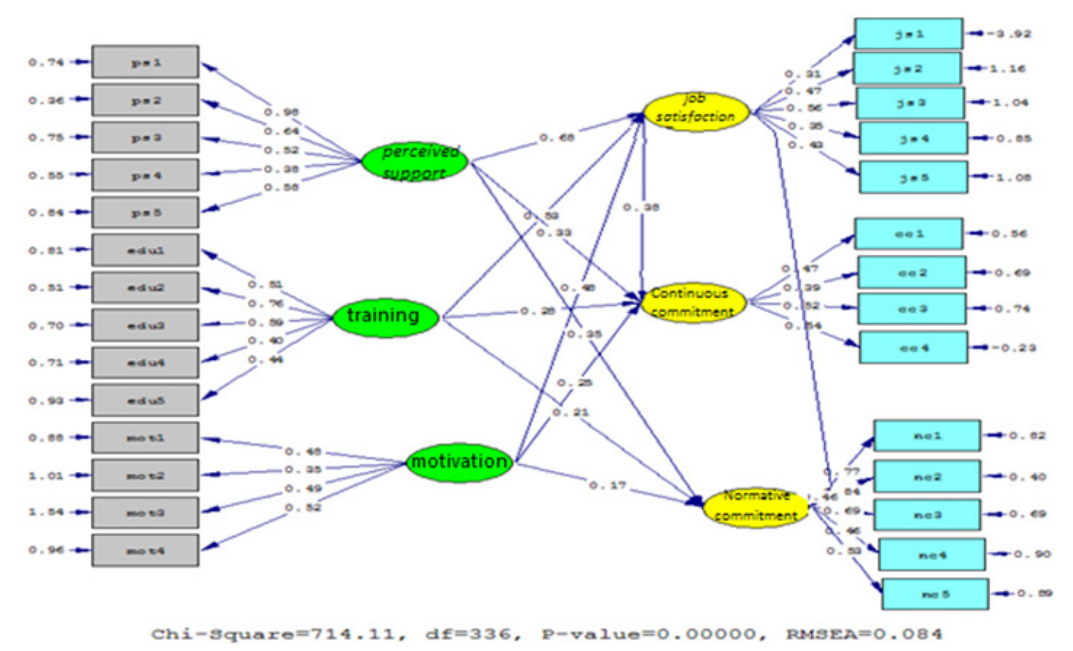

Figure 3 Faction cofficients and first structural model route coefficient, secondary relation

"Mediating hypothesis" evaluates the mediating role of job satisfaction variable in relation to motivation, perceived support and training, and perceived commitment. In other words, the indirect relation of organizational commitment to motivation, perceived support and training were surveyed. In order to study the indirect relation of dependent variable to independent variable, the following conditions must be adopted. The first condition is: the significance of relation between independent variable and mediator variable must be confirmed. The second condition is: the significance of relation between mediator variable and dependent variable must be confirmed. If above conditions were met, then the indirect significant relation and route coefficient will be produced from multiplying the route coefficient of the relation between independent variable and mediator variable as well as the route coefficient of the relation between mediating variable and independent variable. As noted in the previous parts, the second main hypothesis included the relation between independent and mediating variables and the third main hypothesis included the relation between dependent and mediating variables. In the present study, these hypotheses are accepted and hence, it can be said that the indirect relation between motivation, perceived support and training, and perceived commitments is significant by calculating the coefficient of $0.58 * 0.42=0.24$ With regard to the obtained results and from the first main hypothesis which indicates that the route coefficient is 0.36 , it can be said the indirect effect of motivation, perceived support and training on perceived commitment (0.24) is less than its direct effect (0.36). Table 4 summarizes the results of examination of research hypotheses. In this table, significant level of all theories is more than 1/96 so the hypothesis is confirmed. 
Table 4 The results of examination of research hypotheses

\begin{tabular}{lcc}
\hline Hypotheses & $\begin{array}{c}\text { Route } \\
\text { coefficient }\end{array}$ & $\begin{array}{c}\text { Significance } \\
\text { level }\end{array}$ \\
\hline $\begin{array}{l}\text { Motivation, Perceived support and Training } \rightarrow \text { Perceived } \\
\text { commitment }\end{array}$ & 0.36 & 4.56 \\
Motivation, Perceived support and Training $\rightarrow$ Job satisfaction & 0.58 & 2.05 \\
Job satisfaction $\rightarrow$ Perceived commitment & 0.42 & 3.44 \\
Perceived support $\rightarrow$ Continuance commitment & 0.33 & 19.76 \\
$\begin{array}{l}\text { Perceived support } \rightarrow \text { Normative commitment } \\
\text { Training } \rightarrow \text { Continuance commitment }\end{array}$ & 0.35 & 4.43 \\
Training $\rightarrow$ Normative commitment & 0.28 & 16.71 \\
Motivation $\rightarrow$ Continuance commitment & 0.21 & 4.76 \\
$\begin{array}{l}\text { Motivation } \rightarrow \text { Normative commitment } \\
\text { Job satisfaction } \rightarrow \text { Continuance commitment }\end{array}$ & 0.25 & 9.44 \\
$\begin{array}{l}\text { Job satisfactionNormative } \rightarrow \text { commitment } \\
\text { Motivation, Perceived support and Training } \rightarrow \text { Job satisfaction }\end{array}$ & 0.24 & -4.42 \\
\hline
\end{tabular}

\section{Discussion}

Theorists and managers believe that organization effort to provide employee's needs can lead to employees' effort for meeting organization goals toward its outlook. Therefore, employees' understanding about organizational internal collaboration has a direct effect on employees' commitment and organization targets, so activities known as motivation, perceived support and training play an important role in strengthening relations between individuals and organization. According to the results of this study, motivation, perceived support and training are among affecting factors on perceived commitment. In fact, it can be said that motivation, perceived support and training are useful instruments for enabling organizations to respond customers effectively and finally improve perceived commitment. These results are in agreement with the results obtained in earlier studies conducted by KhalafAhmad and Al-Borie [11], Amirkabiri et al. [4] and Salehisedghiani et al. [15]. Also, performing programs on motivation, perceived support and training has an important role in employees' job satisfaction as internal customers of the organization as it has been shown by lliopoulos and Priporas [16] and Ting [12]. On the other hand, employees' job satisfaction causes continuance and normative commitment and finally leads to extended working societies. In fact, employees who have job satisfaction will contribute actively in the organization and have fewer tendencies to leave the organization and take new job opportunities and so they probably have better performance in the organization. The results of this research are in agreement with the findings of Gholampour [17], Rohi et al. [18], Shiuan and Relley [19], and Allen and Meyer [9]. The findings of these studies indicate that motivation, perceived support, and training through educating individuals and motivating them in their jobs as well as supporting them in the organization can lead employees to less likelihood of job relinquishment, lack of absence from work, increase of loyalty, and 
totally leads them to increased continuance and normative commitment to the organization. These findings are in agreement with those obtained by Khalaf Ahmad and Al-Borie [11] and Amirkabiri et al. [4]. According to the findings of this study, motivation, perceived support and training have significant positive effects on perceived commitment with mediating role of job satisfaction. This has also been confirmed in the study of Ting [12].

Considering the aboveresults, it is recommended for directors of institutions and decision-makers to improve the organization by providing appropriate medium to increase job satisfaction of their employees and consequently improve their loyalty to the organization. It would be important to set up training courses or seminars for managers and employees on this issue in the context of motivation, perceived support and training and create a database in the field and update it regularly. In addition, it can provide for employees job satisfaction by giving opportunities to get promoted in the organizational chart, recognizing their achievements on behalf of management, using incentive mechanisms, and rewarding employee for good services. These factors can lead employees to be loyal to their organization and less likelihood of leaving the organization for better job opportunities and provide appropriate medium to develop the organization.

\section{Conclusion}

In sum, the findings showed the effect of motivation, perceived support and training on perceived commitment with mediating role of job satisfaction. This means that staff training and motivating them to increase their job satisfaction which increases productivity and caring staff within the organization, belonging to them in the workplace, increasing the quantity and quality of work, boost the morale of employees and their loyalty to the organization. Also job satisfaction affects on key issues such as the delay, absenteeism, desertion. One limitation in this study was lack of co-staff of the Sabzevar city municipality in the completed questionnaires.

\section{Acknowledgements}

We should express our gratitude and appreciation to all those involved in Sabzevar city municipality.

\section{Contribution}

Study design: NSS, MP

Data collection and analysis: NSS, MP

Manuscript preparation and editing: NSS, MP

\section{Conflict of Interest}

"The authors declare that they have no competing interests."

\section{Funding}

The author (s) received no financial support for the research, authorship and/or publication of this article.

\section{References}

1- Freund A, Carmeli A. The relationship between work commitment and organizational citizenship behavior among lawers in the private sector. Journal of Behavioral and Applied Management2003; 5(2): 91184.

2- Seyed Javadin S, Rayej H, Aghamiri A, Yazdani H. Internal marketing: a Step towards improving organizational citizenship behaviors and of services quality. Journal of Management Researches in Iran2010; 14(2): 67-98.

3- Ballantyne D. A relationship-mediated theory of internal marketing. Eur J Mark2003; 37(2): 1242-60.

4- Amirkabiri A, Mirabi V, Salehisedighani P. Investigation on the effect of internal marketing activities on organizational commitment elements. Journal of Studies of Improvement and Change Management2011; 4(65): 27-46.

5- Doaei H, Borjalilou Sh. The relations between perceived organizational support and organizational commitment and intention to leave the organization. Journal of Prospects for Governmental Administration2010; 1(3): 63-77.

6- Eisenberger R, Huntington R, Hutchison S, Sowa D. Perceived organizational support. J Appl Psychol1986; 71(3): 500-7.

7- Porter LW, Steers RM, Mowday RT, Boulian PV. Organizational commitment, job satisfaction, and turnover among psychiatric technicians. $J$ Appl Psychol1974; 59(5): 603-9. 
8- Yaghoubi M. The relations between organizational justice and organizational commitment and job satisfaction among employees in selected hospitals of Isfahan university of medical sciences. Journal of Health Management2009; 5(35): 27-36.

9- Allen NJ, Meyer JP. The measurement and antecedents of affective continuence and normative commitment to the organization. J Occup Organ Psychol1990; 63(1) : 1-18. 10- Fisher VE, Hanna JV. The dissatisfied worker. New York: Macmillan; 1931.

11- Khalaf A, Al-Borie H. Impact of internal marketing on job satisfaction and organizational commitment: a study of teaching hospitals in Saudi Arabia. Business and Management Research2012; 1(3): 82-94.

12- Ting SC. The effect of internal marketing on organizational commitment: job involvement and job satisfaction as mediators. Educ Adm Q2011; 47(2): 353-82. 13- Spector PE. Measurement of human service staff satisfaction: development of the job satisfaction survey. Am J Community Psychol1985; 13(6): 693-713.

14- Khaki GH. The method with the approach of the dissertation. Ninth edition. Tehran: Publications Baztab; 2011.
15- Salehisedghiani P, Tajzadehnamin, A, Daroueiyan $\mathrm{S}$. The effects of internal marketing on organizational commitment Eteka holding. Journal of Researches in Management2014; 5(1): 195-224.

16- Lliopoulos E, Priporas C. The effect of internal marketing on job satisfaction in health services: a pilot study in public hospitals in Northern Greece. BMC Health Serv Res2011; 4(15): 371-85.

17- Gholampour M, Talebpour M, Amirnejad S, Hosseini S. The relations between job satisfaction and organizational commitment among managers and assistants physical education institutions of higher education institutions. Journal of Sports Science2010; 6(12): 25-3.

18- Rohi Gh, Asayesh H, Rahmani H, Abbasi A. The relations between job satisfaction and organizational commitment of nurses working in hospitals of Golestan university of medical sciences. Journal of Payesh2011; 10(2): 285-92.

19- Shiuan CB, Yu JD, Relley JH. Organizational commitment supervisor commitment and employee outcomes in the Chinese context proximal hypothesis. J Organ Behav2003; 24(3): 313-34.

Copyright@ 2016 ASP Ins. This open-access article is published under the terms of the Creative Commons Attribution-NonCommercial 4.0 International License which permits Share (copy and redistribute the material in any medium or format) and Adapt (remix, transform, and build upon the material) under the Attribution-NonCommercial terms. 